\title{
PfMDR2 and PfMDR5 are dispensable for Plasmodium falciparum asexual parasite multiplication but change in vitro susceptibility to anti-malarial drugs
}

\author{
Maarten van der Velden ${ }^{1}$, Sanna R Rijpma ${ }^{1}$, Frans GM Russel1', Robert W Sauerwein ${ }^{2}$ and Jan B Koenderink ${ }^{1 *}$
}

\begin{abstract}
Background: Membrane-associated ATP binding cassette (ABC) transport proteins hydrolyze ATP in order to translocate a broad spectrum of substrates, from single ions to macromolecules across membranes. In humans, members from this transport family have been linked to drug resistance phenotypes, e.g., tumour resistance by enhanced export of chemotherapeutic agents from cancer cells due to gene amplifications or polymorphisms in multidrug resistance (MDR) protein 1. Similar mechanisms have linked the Plasmodium falciparum PAMDR1 transporter to anti-malarial drug resistance acquisition. In this study, the possible involvement of two related MDR proteins, PAMDR2 and PFMDR5, to emerging drug resistance is investigated by a reverse genetics approach.
\end{abstract}

Methods: A homologous double crossover strategy was used to generate $P$. falciparum parasites lacking the Pfmdr2 (Pf $\Delta m d r 2)$ or Pfmdr5 (Pf $\Delta m d r 5$ ) gene. Plasmodium lactate dehydrogenase activity was used as read-out for sensitivity to artemisinin (ART), atovaquone (ATO), dihydroartemisinin (DHA), chloroquine (CQ), lumefantrine (LUM), mefloquine (MQ), and quinine (QN). Differences in half maximal inhibitory concentration $\left({ }^{\left(C_{50}\right)}\right.$ values between wild type and each mutant line were determined using a paired $t$-test.

Results: Both $P f \Delta m d r 2$ and $P f \Delta m d r 5$ clones were capable of asexual multiplication. Upon drug exposure, $P f \Delta m d r 2$ showed a marginally decreased sensitivity to ATO (IC 50 of $1.2 \mathrm{nM}$ to $1.8 \mathrm{nM}), \mathrm{MQ}(124 \mathrm{nM}$ to $185 \mathrm{nM})$ and QN (40 nM to $70 \mathrm{nM}$ ), as compared to wild type (NF54) parasites. On the other hand, Pf $\Delta m d r 5$ showed slightly increased sensitivity to ART (IC 50 of $26 \mathrm{nM}$ to $19 \mathrm{nM}$ ).

Conclusion: Both Pfmdr2 and Pfmdr5 are dispensable for blood stage development while the deletion lines show altered sensitivity profiles to commonly used anti-malarial drugs. The findings show for the first time that next to PAMDR2, the PAMDR5 transport protein could play a role in emerging drug resistance.

Keywords: ABC transporter, MDR, PFMDR2, PfMDR5, Anti-malarial, Plasmodium falciparum, Malaria

\section{Background}

ATP binding cassette $(\mathrm{ABC})$ transporters are membranebound proteins that translocate a wide variety of substrates, including sugars, peptides, inorganic ions, proteins, and drugs across membranes by consumption of ATP, even against high concentration gradients [1,2]. These transport proteins either consist of two domains, a transmembrane

\footnotetext{
* Correspondence: Jan.Koenderink@radboudumc.nl

'Department of Pharmacology and Toxicology, Radboud University Medical Center, Nijmegen, The Netherlands

Full list of author information is available at the end of the article
}

domain with six membrane-spanning $\alpha$-helices and a nucleotide-binding domain (half transporter) or four domains, two from each of the above alternating each other (full transporter). The nucleotide-binding domain is characteristic for $\mathrm{ABC}$ transport proteins and contains conserved Walker A and B motifs to bind ATP and an $\mathrm{ABC}$ signature sequence $[3,4]$. It is well described that the human P-glycoprotein, a member of the B subfamily of $\mathrm{ABC}$ transport proteins, also known as multidrug resistance (MDR) proteins, provides tumour resistance to chemotherapeutics by extrusion of these substances from 
cancer cells due to MDR1 gene amplifications or polymorphisms [2,5-7]. Based on sequence identity, Plasmodium falciparum has been shown to contain $16 \mathrm{ABC}$ family members in its genome [8], some of which also play important roles in drug resistance development in this parasite.

Plasmodium falciparum causes the most dangerous type of malaria, a life-threatening disease that affected 198 million individuals with an estimated 584,000 fatalities in 2013, especially African children under five [9]. Although treatable, recent reports showed emerging resistance as measured by prolonged parasite clearance times against artemisinin, the fast-acting drug in the first-line artemisinin-based combination therapy (ACT), on the Thai-Cambodian border and in Western Cambodia $[10,11]$. Whereas mutations in the K13-propeller have been identified as molecular markers for increased parasite half-life, additional loci involved in artemisinin resistance are yet to be discovered [12]. Furthermore, amplification of and polymorphisms in the P. falciparum $m d r 1$ and $m r p 1$ genes have been associated with, e.g., artemisinin, chloroquine, lumefantrine, mefloquine, and quinine resistance [13-18]. In addition, polymorphisms and differential Asn-repeat lengths found in Pfmdr6 were shown to alter drug sensitivity to artesunate and piperaquine [19-22], while a single mutation in the heavy metal transporting PfMDR2 [23] was linked to in vitro pyrimethamine resistance, which however, depended on $d h f r$ mutation status [24]. These findings show an important role for $\mathrm{ABC}$ transport proteins in $P$. falciparum drug resistance acquisition. Although the contribution of the MDR family in emerging drug resistance seems evident, as of yet no studies have assessed the effect of Pfmdr deletion lines on altered drug sensitivity.

Here, using a reverse genetics approach, both $P f m d r 2$ and Pfmdr5 were targeted for gene deletion. Subsequently, the involvement of two P. falciparum genes, Pfmdr2 and $P f m d r 5$, on drug sensitivity to seven well-established antimalarial drugs, including artemisinin (ART), atovaquone (ATO), dihydroartemisinin (DHA), chloroquine (CQ), lumefantrine (LUM), mefloquine (MQ), and quinine $(\mathrm{QN})$, belonging to four different drug classes (4-aminoquinolines, artemisinins, aryl-amino alcohols, and naphtoquinones), was studied [25].

\section{Methods}

\section{Parasite cultivation}

Plasmodium falciparum wild type (NF54) and mutant lines $P f \Delta m d r 2$ and $P f \Delta m d r 5$ were cultured in a semiautomated system as described previously [26,27]. Briefly, parasites were grown in vitro in 5\% haematocrit in RPMI medium supplemented with human serum (complete medium), which was changed twice daily. Human red blood cells were refreshed weekly and obtained from the Dutch national blood bank (Sanquin, Nijmegen).

\section{Generation and genotyping of $P f \Delta m d r 2$ and $P f \Delta m d r 5$ parasites}

Plasmodium falciparum $m d r 2$ and $m d r 5$ genes were stably deleted according to a homologous double crossover strategy $[28,29]$. Deletion constructs were based on the reported pHHT-FRT-(GFP)-Pf52 construct in which the homologous regions were replaced with $m d r 2$ and $m d r 5$ target regions (TRs), respectively [30]. These regions were generated by amplifying $P$. falciparum NF54 genomic DNA (gDNA) using PfuUltra II Fusion HS DNA Polymerase (Bio-Connect B.V., Huissen, The Netherlands) with primers (P) P9 and $\mathrm{P} 10$ for the $5^{\prime}$ target region and primers P11 and P12 for the 3' TR of $m d r 2$, respectively. Similarly, primers P13-P16 were used to generate TRs for mdr5 (Additional file 1: Table S1). Following TOPO TA subcloning (Life Technologies Europe B.V., Bleiswijk, The Netherlands) of the amplified TRs, these were validated by restriction digestion and sequencing. Then, $5^{\prime}$ and $3^{\prime}$ TRs from each $m d r$ gene were cloned in the pHHT-FRT(GFP)-Pf52 construct using BssHII plus BsiWI and XmaI plus NheI restriction enzymes, respectively. This resulted in two deletion constructs, pHHT-FRT-(GFP)-Pfmdr2 and pHHT-FRT-(GFP)-Pfmdr5. Transfection and selection were performed as previously described [30], resulting in two $m d r$ mutant lines. Both lines were subsequently transfected with the pMV-FLPe construct in order to excise heterologous DNA (hdhfr::gfp selectable marker) flanked by flippase recognition target (FRT) sites using enhanced flippase (FLPe) recombinase [30]. Following limiting dilution, two cloned mutant lines, Pf $\Delta m d r 2$ and $P f \Delta m d r 5$ were derived for downstream analysis.

Genotype analysis of the parasite mutants was performed using Expand Long Range dNTPack (Roche Diagnostics Nederland B.V., Almere, The Netherlands) (LR-PCR). Mixed asexual blood stage gDNA from wild type and deletion parasites was isolated using the QIAamp DNA Blood Mini Kit (Qiagen N.V., Venlo, The Netherlands). Primers P1 and P2 plus P5 and P6 (Additional file 1: Table S1) designed to flank the $5^{\prime}$ and $3^{\prime}$ TRs for $m d r 2$ and $m d r 5$, respectively, were used to analyse wild type and mutant DNA using LR-PCR for correct double homologous crossover integration. The LR-PCR started with an initial denaturation at $94^{\circ} \mathrm{C}$ for $5 \mathrm{~min}$, followed by 35 cycles of denaturation at $94^{\circ} \mathrm{C}$ for $30 \mathrm{sec}$, annealing at $43.5-50^{\circ} \mathrm{C}$ ( $43.5^{\circ} \mathrm{C}$ for wild type and mutant $m d r 2,46^{\circ} \mathrm{C}$ for wild type $m d r 5$ and $50^{\circ} \mathrm{C}$ for mutant $m d r 5$ ) for $30 \mathrm{sec}$, elongation at $60^{\circ} \mathrm{C}$ for $15 \mathrm{~min}$ [31] and a final elongation step at $62^{\circ} \mathrm{C}$ for $15 \mathrm{~min}$. An additional intra-exonic PCR was performed on gDNA using primers $\mathrm{P} 3$ and $\mathrm{P} 4$ and $\mathrm{P} 7$ and $\mathrm{P} 8$ designed within the gene exon of both $m d r$ genes (Additional file 1: Table S1). Briefly, gDNA from wild type and mutant lines was isolated as described 
above and amplified using Taq DNA polymerase (Life Technologies Europe B.V., Bleiswijk, The Netherlands). Denaturation at $94^{\circ} \mathrm{C}$ for $2 \mathrm{~min}$ was followed by 40 cycles of denaturation at $94^{\circ} \mathrm{C}$ for $15 \mathrm{sec}$, annealing at $52^{\circ} \mathrm{C}$ for $45 \mathrm{sec}$ and elongation at $60^{\circ} \mathrm{C}$ for $30 \mathrm{sec}$, followed by a final elongation step at $60^{\circ} \mathrm{C}$ for $2 \mathrm{~min}$.

\section{Anti-malarial sensitivity assays}

ART, ATO, CQ, DHA, LUM, MQ, and QN were all purchased from Sigma-Aldrich Chemie B.V. (Zwijndrecht, The Netherlands). ART and QN were dissolved in methanol, ATO, DHA, LUM, and MQ were dissolved in DMSO, $\mathrm{CQ}$ was dissolved in complete medium (described above) and serial dilutions of all drugs were stored at $-20^{\circ} \mathrm{C}$ and thawed prior to use. Anti-malarial sensitivity assays were performed in at least three independent consecutive experiments using a slightly modified Plasmodium lactate dehydrogenase (pLDH) method as described previously [32]. In short, $50 \mu \mathrm{L}$ of serially diluted drugs was added to black, clear-bottom, 96-well, cell culture plates (Greiner Bio-One B.V., Alphen a/d Rijn, The Netherlands) in triplicate (duplicate for the 0 concentrations). Then, $50 \mu \mathrm{L}$ mixed asexual stage wild type (NF54) and mutant parasites (2.5\% parasitaemia in $1 \%$ final haematocrit) was added to each drug-containing well. Following incubation for $72 \mathrm{hrs}$ at $37^{\circ} \mathrm{C}$ in a candle jar [33], the 96-well plates were frozen for at least $3 \mathrm{hrs}$ at $-20^{\circ} \mathrm{C}$. After thawing the plates, parasite $\mathrm{pLDH}$ activity was measured by adding $70 \mu \mathrm{L}$ of freshly made reaction mix $(286 \mathrm{mM}$ sodium L-lactate (Sigma-Aldrich Chemie B.V., Zwijndrecht, The Netherlands), $286 \mathrm{mM}$ 3-acetyl pyridine adenine dinucleotide (Sigma-Aldrich Chemie B.V., Zwijndrecht, The Netherlands), $357.5 \mu \mathrm{M}$ resazurin (Sigma-Aldrich Chemie B.V., Zwijndrecht, The Netherlands), $5.66 \mathrm{U} / \mathrm{mL}$ diaphorase (Worthington Biochemical Corp., Lakewood, NJ, USA), 1.4\% Tween-20 (Sigma-Aldrich Chemie B.V., Zwijndrecht, The Netherlands), $20 \mathrm{mM}$ Tris- $\mathrm{HCl} \mathrm{pH} \mathrm{8.0)}$ to each well. Next, the plates were incubated in darkness for 30-60 min and absorbance was measured at $590 \mathrm{~nm}$ after excitation at $530 \mathrm{~nm}$ using a Synergy 2 MultiMode Microplate Reader (Bio-Tek, Bad Friedrichshall, Germany). The logarithm of half maximal inhibitory concentration $\left(\log \mathrm{IC}_{50}\right)$ values were determined by nonlinear regression fitting of dose-response inhibition curves with variable slopes using GraphPad Prism version 5.03 (GraphPad Software, Inc., La Jolla, CA, USA). For each anti-malarial drug, Hill slopes were fixed to the average of all non-ambiguous slopes for each $m d r$ mutant and their wild type control. Comparisons for significant differences between the obtained $\log \mathrm{IC}_{50^{-}}$ values of wild type and mutant groups were carried out by a paired $t$-test. Finally, the plotted curves represent the combined averages of each individual anti-malarial assay per line, where the top of each curve fit was set to $100 \%$.

\section{Results}

Plasmodium falciparum mdr2 and mdr5 are dispensable for asexual blood stage multiplication

Possible drug resistance association of two $P$. falciparum MDR transport proteins, PfMDR2 and PfMDR5, were studied by a reverse genetics approach. In order to generate stable Pfmdr2 and Pfmdr5 gene deletion asexual stage mutants, a homologous double crossover strategy was used $[28,29]$ with the pHHT-FRT-(GFP)-Pfmdr2 and pHHT-FRT-(GFP)-Pfmdr5 deletion constructs (Figure 1A and B). Heterologous DNA including the hdhfr::gfp selectable marker flanked by FRT sites was subsequently removed from the mutant parasites using FLP-mediated sequence excision [30]. Diagnostic long-range PCR (LR-PCR) reactions were performed to validate the lines lacking the endogenous Pfmdr2 (Pf $\Delta m d r 2$ ) and Pfmdr5 (Pf $\Delta m d r 5$ ) genes. LR-PCR using primers (P) P1 and P2 flanking the target regions resulted in the expected amplification products of 5,571 bp and 2,553 bp for gDNA from NF54 wild type and $P f \Delta m d r 2$ parasites, respectively (Figure $1 C$ ). Similarly, wild type and Pf $\Delta m d r 5$ gDNA was amplified using P5 and P6, producing amplicons of 5,028 bp and $2,303 \mathrm{bp}$, respectively (Figure $1 \mathrm{C}$ ). To ensure that neither of the wild type genes was still present, intra-exonic PCRs were performed using P3 and P4 plus P7 and P8 within the exons of $P f m d r 2$ and $P f m d r 5$, respectively. For the Pfmdr2 gene, PCR amplification of wild type gDNA resulted in a 92 bp product, whereas no amplification was seen in the $P f \Delta m d r 2$ line as expected (Figure 1D). Analogously, a 96 bp product was generated from wild type gDNA using the Pfmdr5 primers, unlike $P f \Delta m d r 5$ gDNA where no product could be obtained (Figure 1D). Both generated mutants showed unaltered morphology and growth rate (data not shown). Combined, these results show that both Pfmdr2 and Pfmdr5 genes were successfully deleted and not required for $P$. falciparum asexual blood stage multiplication.

\section{Both Pfmdr2 and Pfmdr5 modulate Plasmodium falciparum drug susceptibility}

To assess whether Pfmdr2 and Pfmdr5 could play a role in $P$. falciparum susceptibility to anti-malarial drugs, both $P f \Delta m d r 2$ and $P f \Delta m d r 5$ mutants were subjected to a panel containing seven drug compounds (ART, ATO, CQ, DHA, LUM, MQ, and QN) and altered sensitivity to any of the drugs was assessed compared to wild type (NF54). No difference in sensitivity to ART, CQ, DHA, and LUM was observed for the Pf $\Delta m d r 2$ mutant (Figure 2A, C-E). Upon deletion of $P f m d r 2$, sensitivity to ATO $(n=7)$ marginally decreased, as is shown by an increase in average $\mathrm{IC}_{50}$ from $1.2 \mathrm{nM}$ (95\% CI 0.9-1.5 nM) (wild type) to 1.8 $\mathrm{nM}(95 \%$ CI 1.3-2.5 nM) (Pf $\Delta m d r 2, \mathrm{p}=0.017)$ (Figure 2B). Furthermore, $P f \Delta m d r 2$ parasites also became less sensitive to MQ $(n=6)$ and QN $(n=4)$, both belonging to the 


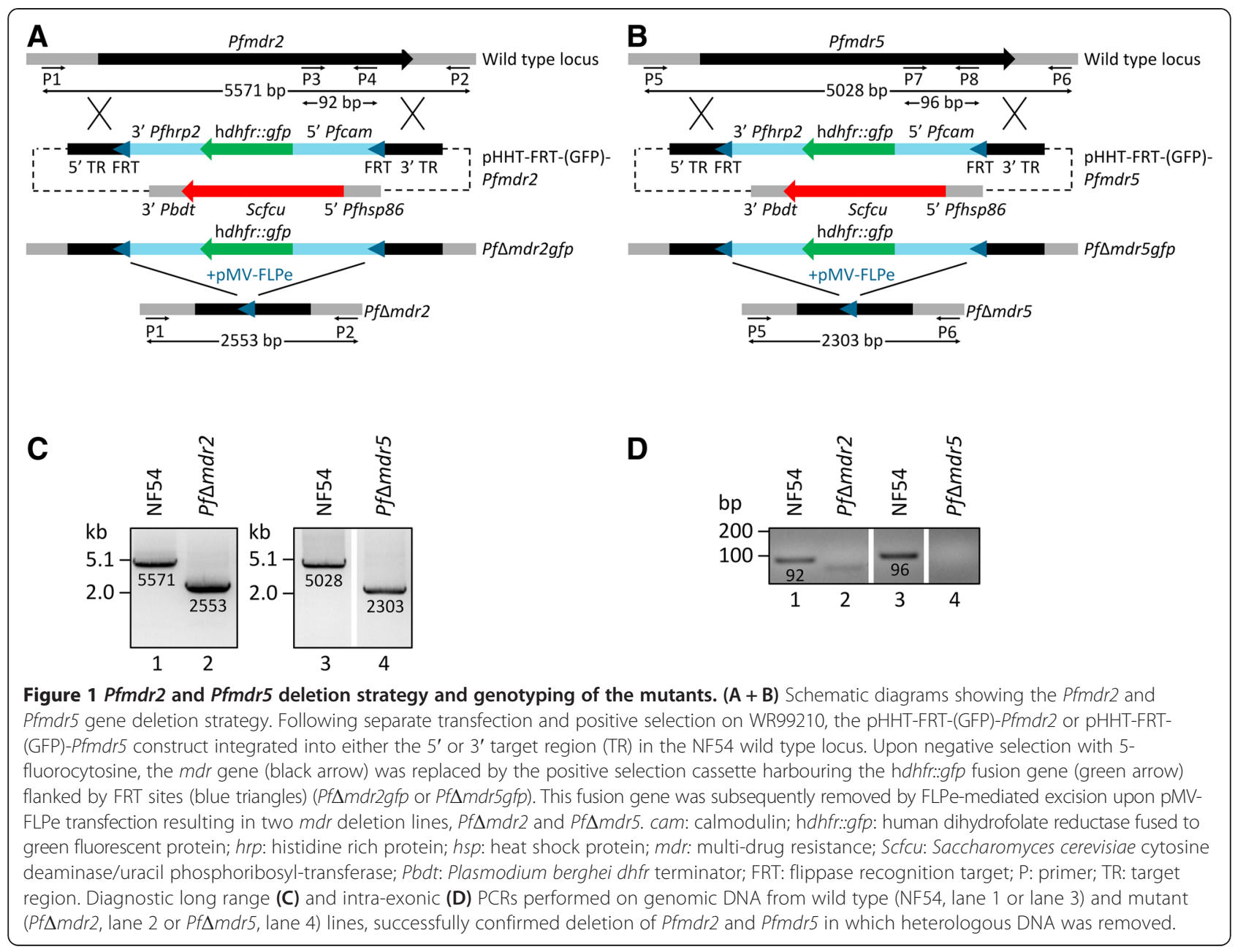

aryl-amino alcohol class of anti-malarials [25]. For both drugs, sensitivity was reduced significantly, with an average $\mathrm{IC}_{50}$ of $124 \mathrm{nM}(95 \% \mathrm{CI} 86-180 \mathrm{nM})$ against MQ in wild type to $185 \mathrm{nM}(95 \%$ CI $145-234 \mathrm{nM})$ in $P f \Delta m d r 2$ parasites $(\mathrm{p}=0.004)$, and an $\mathrm{IC}_{50}$ of $40 \mathrm{nM}(95 \%$ CI $27-60 \mathrm{nM})$ in wild type to $70 \mathrm{nM}(95 \%$ CI $57-85 \mathrm{nM}$ ) in Pf $\Delta m d r 2$ parasites for $\mathrm{QN}(\mathrm{p}=0.022)$ (Figure $2 \mathrm{~F}-\mathrm{G})$. No difference in sensitivity to ATO, CQ, DHA, LUM, MQ, and QN was detected for the $P f \Delta m d r 5$ mutant (Figure $2 \mathrm{~B}-\mathrm{G}$ ). In contrast, for ART ( $\mathrm{n}=5)$, the $\mathrm{IC}_{50}$ of $P f \Delta m d r 5$ mutant parasites decreased slightly but significantly $(\mathrm{p}=0.046)$ from an average of $26 \mathrm{nM}$ (95\% CI 19-36 nM) in wild type to $19 \mathrm{nM}$ (95\% CI $14-27 \mathrm{nM}$ ) in Pf $\Delta m d r 5$ parasites, highlighting ART as being the single compound showing an increase in sensitivity following $m d r$ deletion in this study (Figure 2A).

\section{Discussion}

Increasing $P$. falciparum resistance to anti-malarial drugs is a major threat for effective malaria treatment. For this reason, it is important to unravel proteins and mechanisms that contribute to drug resistance. While involvement of the PfMDR1 transport protein in P. falciparum drug resistance is evident, little is known about contribution of other P. falciparum MDR members. Thus, using a reverse genetics approach, the aim of this study was to determine whether PfMDR2 and PfMDR5 could play a role in decreased drug sensitivity development using a panel of seven anti-malarials. Both $P f \Delta m d r 2$ and Pf $\Delta m d r 5$ mutant lines were able to complete asexual development, highlighting that during this stage the transport proteins are dispensable for parasite viability. It is hypothesized that $P f \Delta m d r 2$ and $P f \Delta m d r 5$ become more susceptible to the tested anti-malarials if: i) the anti-malarial is a substrate for the wild type transporter; and, ii) the wild type MDR protein is located on the plasma membrane, which in the case of mutant lines would result in accumulation of the compounds within the parasite followed by its demise.

In contrast to the hypothesis above, deletion of P. falciparum $m d r 2$ induced some decrease in sensitivity to the anti-malarials ATO, MQ and QN. As PfMDR2 has been reported to localize to the plasma membrane of the parasite [34], deleting this protein would result in accumulation of substrate anti-malarials within the 


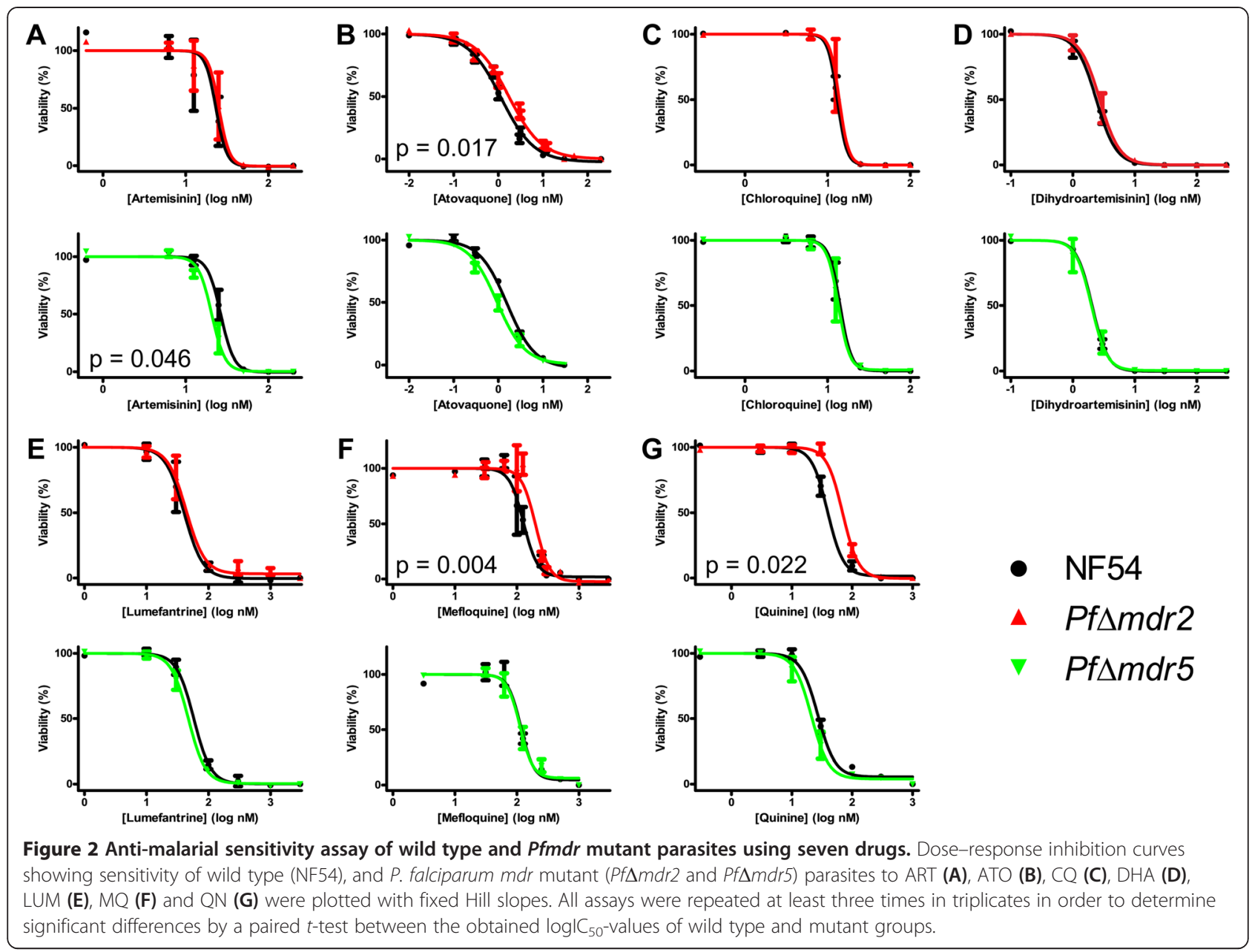

parasite, leading to an increased sensitivity phenotype. However, besides plasma membrane association, PfMDR2 expression on the food vacuole has also been proposed $[23,35]$. MQ and QN are incorporated into growing haemozoin polymers within the food vacuole [36] and therefore are toxic to the parasite, hence, deletion of PfMDR2 might prevent accumulation of these drugs in the digestive vacuole, resulting in decreased sensitivity of $P f \Delta m d r 2$ to $\mathrm{MQ}$ and $\mathrm{QN}$ as shown here. In contradiction to these results, it has been reported that MQ and potentially QN prevent uptake of host cell hemoglobin by inhibiting endocytosis $[37,38]$ and therefore it may be advantageous for $P$. falciparum to sequester these drugs in the food vacuole [39]. However, at this stage, it is unclear whether MQ and QN accumulation in the food vacuole is indeed affected by Pfmdr2 deletion. While LUM belongs to the same drug class as MQ and QN [25], the Pf $\Delta m d r 2$ mutant does not show the same trend in sensitivity to LUM as compared to the latter drugs. This might indicate that LUM is not a substrate for Pfmdr2 or (less likely) it has a different site of action, which currently is undetermined. ATO exerts its anti-malarial activity by inhibiting the parasite's oxygen consumption in mitochondria [40]. While mitochondrial localization of PfMDR2 has not been shown, further research may link PfMDR2 deletion to decreased ATO sensitivity. Moreover, it would be interesting to test several drug combinations to observe synergistic effects. These findings indicate that PfMDR2 may be involved in drug sensitivity either directly or indirectly via drug substrates.

Upon deletion of $P$. falciparum $m d r 5$, only sensitivity to ART was altered. In concordance with the hypothesis, parasites lacking PfMDR5 became slightly more sensitive to ART, suggesting that this drug is a possible substrate for the PfMDR5 transport protein. As PfMDR5 has previously been shown to localize to the parasite's plasma membrane [41], lacking this transport protein could lead to an accumulation of ART in the parasite, hence, resulting in increased sensitivity. On the contrary, there was no difference in sensitivity for Pf $\Delta m d r 5$ versus wild type parasites to DHA, the active metabolite of artemisinin derivatives [42], highlighting a possible subtle difference in substrate specificity. 


\section{Conclusions}

Plasmodium falciparum does not require PfMDR2 and PfMDR5 to progress through the asexual multiplication cycle. Additionally, deletion of PfMDR2 resulted in a minor decreased sensitivity phenotype to ATO, MQ and QN. Therefore, $P$. falciparum might increase its resistance to these anti-malarials by modulating PfMDR2 in order to prevent these drugs from reaching their proposed target sites. Moreover, the PfMDR5 deletion mutant became slightly more sensitive upon exposure to ART, suggesting that over-expression or enhanced activity of this protein might contribute to ART resistance.

\section{Additional file}

Additional file 1: Table S1. Diagnostic long-range primers, intra-exonic primers and targeting construct primers.

\section{Competing interests}

The authors declare that they have no competing interests.

\section{Authors' contributions}

MV participated in the design of the study, generation of mutant lines, performance of anti-malarial assays, analysis of the data and drafted the manuscript. SRR participated in the drug assays and data analysis. RWS and FGMR participated in the design of the study and revision of the manuscript. JBK conceived the study, its coordination and helped to draft the manuscript. All authors read and approved the final manuscript.

\section{Acknowledgements}

The work of MV is supported by a personal grant from Radboudumc.

\section{Author details}

${ }^{1}$ Department of Pharmacology and Toxicology, Radboud University Medical Center, Nijmegen, The Netherlands. ${ }^{2}$ Department of Medical Microbiology, Radboud University Medical Center, Nijmegen, The Netherlands.

Received: 29 October 2014 Accepted: 25 January 2015

\section{Published online: 14 February 2015}

\section{References}

1. Higgins CF. ABC transporters: from microorganisms to man. Annu Rev Cell Biol. 1992:8:67-113.

2. Rees $\mathrm{DC}$, Johnson $\mathrm{E}$, Lewinson $\mathrm{O}$. $\mathrm{ABC}$ transporters: the power to change. Nat Rev Mol Cell Biol. 2009;10:218-27.

3. Walker JE, Saraste M, Runswick MJ, Gay NJ. Distantly related sequences in the alpha- and beta-subunits of ATP synthase, myosin, kinases and other ATP-requiring enzymes and a common nucleotide binding fold. EMBO J. 1982;1:945-51

4. Hyde SC, Emsley P, Hartshorn MJ, Mimmack MM, Gileadi U, Pearce SR, et al. Structural model of ATP-binding proteins associated with cystic fibrosis, multidrug resistance and bacterial transport. Nature. 1990;346:362-5.

5. Gottesman MM, Hrycyna CA, Schoenlein PV, Germann UA, Pastan I. Genetic analysis of the multidrug transporter. Annu Rev Genet. 1995;29:607-49.

6. Gottesman MM, Pastan I, Ambudkar SV. P-glycoprotein and multidrug resistance. Curr Opin Genet Dev. 1996;6:610-7.

7. Ling V, Gerlach J, Kartner N. Multidrug resistance. Breast Cancer Res Treat. 1984:4:89-94.

8. Koenderink JB, Kavishe RA, Rijpma SR, Russel FG. The ABCs of multidrug resistance in malaria. Trends Parasitol. 2010;26:440-6.

9. WHO. Malaria Fact sheet N94. Geneva: World Health Organization; 2014

10. Dondorp AM, Nosten F, Yi P, Das D, Phyo AP, Tarning J, et al. Artemisinin resistance in Plasmodium falciparum malaria. N Engl J Med. 2009;361:455-67.

11. Amaratunga C, Sreng S, Suon S, Phelps ES, Stepniewska K, Lim P, et al. Artemisinin-resistant Plasmodium falciparum in Pursat province, western Cambodia: a parasite clearance rate study. Lancet Infect Dis. 2012;12:851-8.
12. Ariey F, Witkowski B, Amaratunga C, Beghain J, Langlois AC, Khim N, et al. A molecular marker of artemisinin-resistant Plasmodium falciparum malaria. Nature. 2014;505:50-5.

13. Foote SJ, Thompson JK, Cowman AF, Kemp DJ. Amplification of the multidrug resistance gene in some chloroquine-resistant isolates of $P$. falciparum. Cell. 1989;57:921-30.

14. Peel SA, Bright P, Yount B, Handy J, Baric RS. A strong association between mefloquine and halofantrine resistance and amplification, overexpression, and mutation in the P-glycoprotein gene homolog (pfmdr) of Plasmodium falciparum in vitro. Am J Trop Med Hyg. 1994;51:648-58.

15. Raj DK, Mu J, Jiang H, Kabat J, Singh S, Sullivan M, et al. Disruption of a Plasmodium falciparum multidrug resistance-associated protein (PFMRP) alters its fitness and transport of antimalarial drugs and glutathione. J Biol Chem. 2009;284:7687-96.

16. Veiga MI, Ferreira PE, Jornhagen L, Malmberg M, Kone A, Schmidt BA, et al Novel polymorphisms in Plasmodium falciparum ABC transporter genes are associated with major ACT antimalarial drug resistance. PLOS One. 2011;6:e20212.

17. Hao M, Jia D, Li Q, He Y, Yuan L, Xu S, et al. In vitro sensitivities of Plasmodium falciparum isolates from the China-Myanmar border to piperaquine and association with polymorphisms in candidate genes. Antimicrob Agents Chemother. 2013;57:1723-9.

18. Phompradit P, Muhamad P, Wisedpanichkij R, Chaijaroenkul W, Na-Bangchang K. Four years' monitoring of in vitro sensitivity and candidate molecular markers of resistance of Plasmodium falciparum to artesunate-mefloquine combination in the Thai-Myanmar border. Malar J. 2014;13:23.

19. Mu J, Ferdig MT, Feng X, Joy DA, Duan J, Furuya T, et al. Multiple transporters associated with malaria parasite responses to chloroquine and quinine. Mol Microbiol. 2003;49:977-89.

20. Anderson TJ, Nair S, Qin H, Singlam S, Brockman A, Paiphun L, et al. Are transporter genes other than the chloroquine resistance locus (pfort) and multidrug resistance gene (pfmdr) associated with antimalarial drug resistance? Antimicrob Agents Chemother. 2005;49:2180-8.

21. Okombo J, Abdi Al, Kiara SM, Mwai L, Pole L, Sutherland CJ, et al. Repeat polymorphisms in the low-complexity regions of Plasmodium falciparum $A B C$ transporters and associations with in vitro antimalarial responses. Antimicrob Agents Chemother. 2013;57:6196-204.

22. Wang Z, Parker D, Meng H, Wu L, Li J, Zhao Z, et al. In vitro sensitivity of Plasmodium falciparum from China-Myanmar border area to major ACT drugs and polymorphisms in potential target genes. PLoS One. 2012; 7:e30927.

23. Rosenberg E, Litus I, Schwarzfuchs N, Sinay R, Schlesinger P, Golenser J, et al. pfmdr2 confers heavy metal resistance to Plasmodium falciparum. J Biol Chem. 2006;281:27039-45.

24. Briolant S, Bogreau H, Gil M, Bouchiba H, Baret E, Amalvict R, et al. The F423Y mutation in the pfmdr2 gene and mutations N511, C59R, and S108N in the pfdhfr gene are independently associated with pyrimethamine resistance in Plasmodium falciparum isolates. Antimicrob Agents Chemother. 2012;56:2750-2.

25. Rosenthal PJ. The interplay between drug resistance and fitness in malaria parasites. Mol Microbiol. 2013;89:1025-38.

26. Ifediba T, Vanderberg JP. Complete in vitro maturation of Plasmodium falciparum gametocytes. Nature. 1981;294:364-6.

27. Ponnudurai $T$, Lensen $A H$, Leeuwenberg AD, Meuwissen JH. Cultivation of fertile Plasmodium falciparum gametocytes in semi-automated systems. 1. Static cultures. Trans R Soc Trop Med Hyg. 1982;76:812-8.

28. Duraisingh MT, Triglia T, Cowman AF. Negative selection of Plasmodium falciparum reveals targeted gene deletion by double crossover recombination. Int J Parasitol. 2002;32:81-9.

29. Maier AG, Braks JA, Waters AP, Cowman AF. Negative selection using yeast cytosine deaminase/uracil phosphoribosyl transferase in Plasmodium falciparum for targeted gene deletion by double crossover recombination. Mol Biochem Parasitol. 2006;150:118-21.

30. van Schaijk BC, Vos MW, Janse CJ, Sauerwein RW, Khan SM. Removal of heterologous sequences from Plasmodium falciparum mutants using FLPe-recombinase. PLoS One. 2010;5:e15121.

31. Su XZ, Wu Y, Sifri CD, Wellems TE. Reduced extension temperatures required for PCR amplification of extremely A + T-rich DNA. Nucleic Acids Res. 1996;24:1574-5.

32. Gamo FJ, Sanz LM, Vidal J, de Cozar C, Alvarez E, Lavandera JL, et al. Thousands of chemical starting points for antimalarial lead identification. Nature. 2010;465:305-10. 
33. Jensen JB, Trager W. Plasmodium falciparum in culture: use of outdated erthrocytes and description of the candle jar method. J Parasitol. 1977;63:883-6.

34. Rubio JP, Cowman AF. Plasmodium falciparum: the pfmdr2 protein is not overexpressed in chloroquine-resistant isolates of the malaria parasite. Exp Parasitol. 1994;79:137-47.

35. Zalis MG, Wilson CM, Zhang Y, Wirth DF. Characterization of the pfmdr2 gene for Plasmodium falciparum. Mol Biochem Parasitol. 1993;62:83-92.

36. Mungthin M, Bray PG, Ridley RG, Ward SA. Central role of hemoglobin degradation in mechanisms of action of 4-aminoquinolines, quinoline methanols, and phenanthrene methanols. Antimicrob Agents Chemother. 1998;42:2973-7.

37. Hoppe HC, van Schalkwyk DA, Wiehart UI, Meredith SA, Egan J, Weber BW. Antimalarial quinolines and artemisinin inhibit endocytosis in Plasmodium falciparum. Antimicrob Agents Chemother. 2004;48:2370-8.

38. Famin $\mathrm{O}$, Ginsburg H. Differential effects of 4-aminoquinoline-containing antimalarial drugs on hemoglobin digestion in Plasmodium falciparum-infected erythrocytes. Biochem Pharmacol. 2002;63:393-8.

39. Rohrbach P, Sanchez CP, Hayton K, Friedrich O, Patel J, Sidhu AB, et al. Genetic linkage of pfmdr1 with food vacuolar solute import in Plasmodium falciparum. EMBO J. 2006;25:3000-11.

40. Murphy $A D$, Lang-Unnasch N. Alternative oxidase inhibitors potentiate the activity of atovaquone against Plasmodium falciparum. Antimicrob Agents Chemother. 1999:43:651-4.

41. Kavishe RA, van den Heuvel JM, van de Vegte-Bolmer M, Luty AJ, Russel FG, Koenderink JB. Localization of the ATP-binding cassette (ABC) transport proteins PfMRP1, PFMRP2, and PFMDR5 at the Plasmodium falciparum plasma membrane. Malar J. 2009:8:205

42. Navaratnam V, Mansor SM, Sit NW, Grace J, Li Q, Olliaro P. Pharmacokinetics of artemisinin-type compounds. Clin Pharmacokinet. 2000;39:255-70.

\section{Submit your next manuscript to BioMed Central and take full advantage of:}

- Convenient online submission

- Thorough peer review

- No space constraints or color figure charges

- Immediate publication on acceptance

- Inclusion in PubMed, CAS, Scopus and Google Scholar

- Research which is freely available for redistribution 